УДК 620.9 + 621.311.24

\title{
ВЕТРОДВИГАТЕЛЬ ДЛЯ ПОСТРОЕНИЯ АВТОНОМНЫХ КРЫШНЫХ ВЕТРОЭЛЕКТРОСТАНЦИЙ В ИЗОЛИРОВАННЫХ ЗОНАХ
}

\author{
Андрианова Людмила Прокопьевна \\ д-р техн. наук, профессор \\ Павлова Зухра Хасановна \\ д-р техн. наук, профессор \\ Хакимьянов Марат Ильгизович \\ д-р техн. наук, профессор \\ Хазиева Регина Тагировна \\ канд. техн. наук, доцент
}

ФГБОУ ВО Уфимский государственный нефтяной технический университет

Аннотация: В статье описана конструкция ветродвигателя, предназначенного для преобразования ветровой энергии в электрическую энергию. Ветродвигатель выполнен в виде продольного ряда вертикальных валов, связанных между собой зубчатыми колесами, и снабженных радиальными ветровыми лопастями. Зубчатые колеса суммируют мощности всех валов, на одном из них установлен генератор электрической энергии. Предложенная конструктивная схема ветродвигателя может быть использована для построения мощных ветроэлектростанций. Ветродвигатель предназначен для установки на крышах домов в комплексе с автономными солнечными электростанциями, не исключена возможность наземного использования.

Ключевые слова: ветродвигатель продольного типа, ряд вертикальных валов; параллельные диски; продольная ось; зубчатые колеса; радиальные ветровые лопасти; направляющие щиты; крышное или наземное исполнение.

\section{WIND TURBINE FOR BUILDING AUTONOMOUS ROOF WIND FARMS IN ISOLATED AREAS}

\author{
Andrianova Lyudmila Prokofievna \\ Pavlova Zuhra Khasanovna \\ Khakimjanov Marat Ilgizovich \\ Khazieva Regina Tagirovna
}

Abstract: The article describes the design of a wind turbine designed to convert wind energy into electrical energy. The wind turbine is made in the form of a 
longitudinal series of vertical shafts connected by gear wheels, and equipped with radial wind blades. Gear wheels sum up the power of all the shafts, one of them has an electric power generator installed. The proposed design scheme of a wind turbine can be used to build powerful wind farms. The wind turbine is intended for installation on roofs of houses in a complex with Autonomous solar power plants, the possibility of ground use is not excluded.

Key words: wind Turbine of longitudinal type, a number of vertical shafts; parallel disks; longitudinal axis; gear wheels; radial wind blades; guide boards; roof or ground design.

В настоящее время для автономного энергоснабжения различного рода потребителей в изолированных зонах широкое применение находят возобновляемые источники энергии, такие как солнечная и ветровая энергия [15]. Зачастую устройства для их использования монтируют на крышах домов, где имеется свободное солнечное и ветровое пространство. Для монтажа крышных ветроэнергоустановок рекомендуется использовать северную часть крыши, а южную часть - для монтажа солнечных энергоустановок, которые не мешают друг другу, если, конечно, позволяют размеры крыши [1]. Отсюда возникает вопрос компактности и в то же время достаточной мощности энергоустановок при прогнозировании потребительского спроса [3].

Для построения крышных ветроэлектростанций повышенной энергоэффективности авторы статьи предлагают оригинальную конструкцию ветродвигателя, состоящего из ряда вертикальных валов, расположенных на одной геометрической продольной оси, связанных между собой зубчатыми колесами, и снабженных радиальными ветровыми лопастями. Диски зубчатых колес и ветровые лопасти выполнены касательно между собой по сторонам ветровых лопастей. На каждой из них, в поперечной оси установки валов, шарнирно установлены направляющие щиты, ширина которых равна расстоянию между осями соседних вертикальных валов. Зубчатые колеса суммируют мощности всех валов, и на одном из них установлен генератор электрической энергии.

На рис. 1 показан общий вид ветродвигателя, фронтальный вид; на рис. 2 сечение ветродвигателя по А-А; на рис. 3 варианты работы ветродвигателя. 


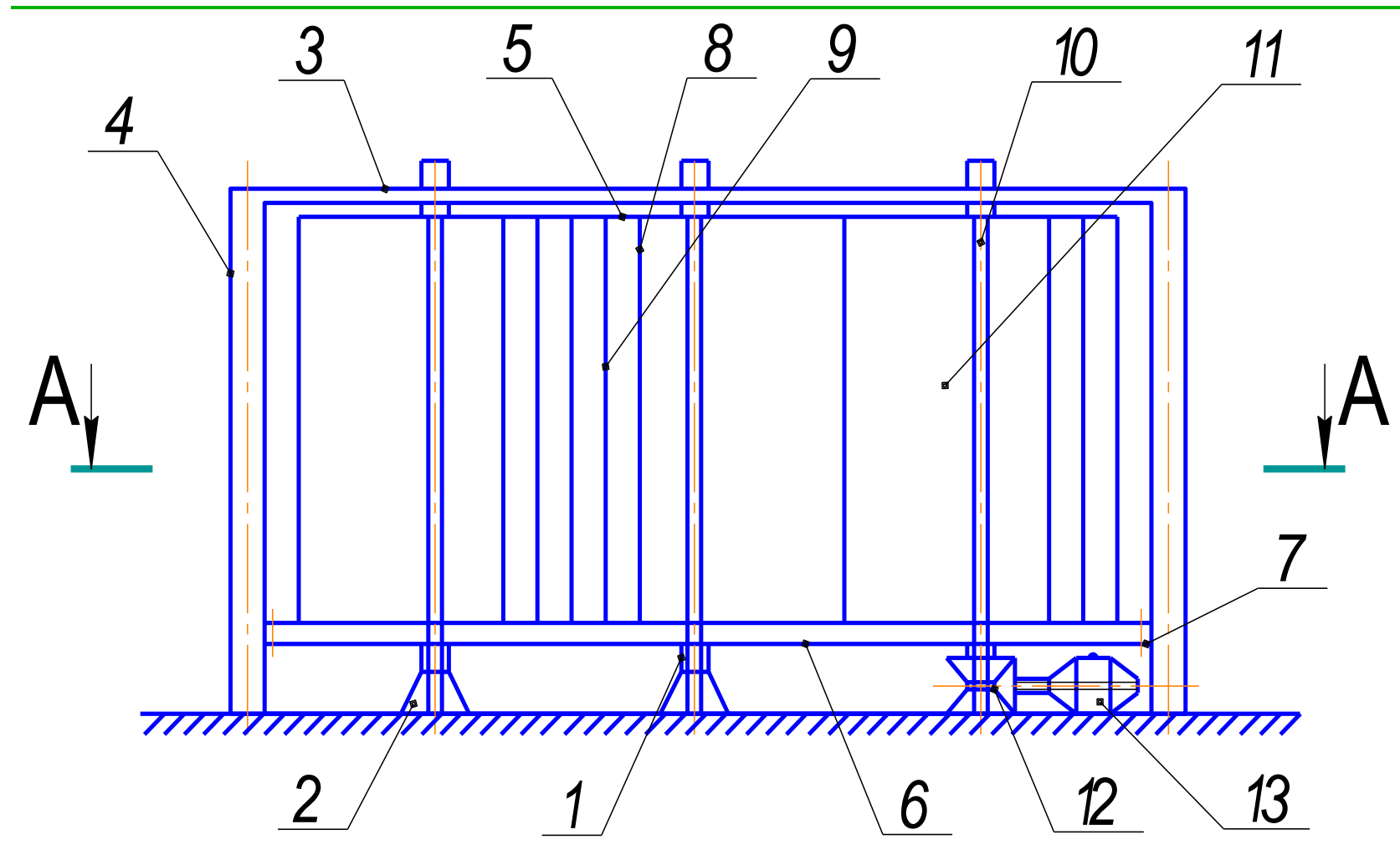

Рис. 1. Общий вид ветродвигателя (фронтальный вид):

1- вертикальный валы; 2 - опорные подшипники; 3 - продольная балка; 4 - стойка; 5- верхний диск; 6 - нижний диск; 7 - зубчатый венец; 8барабан; 9- радиальные чашеобразные ветровые лопасти; 10- шарниры;

\section{1- направляющие щиты;}

\section{2 - зубчатая передача; 13- генератор электрической энергии}

Ветродвигатель включает в себя ряд вертикальных валов 1, установленных на опорных подшипниках в один ряд на одной геометрической продольной оси. Все валы 1 сверху центрируются продольной балкой 3 , закрепленной на стойках 4, снизу и сверху на валах 1 касательно закреплены диски, верхний 5 и нижний 6 , причем нижний диск 6 снабжен зубчатым венцом 7 образуя зубчатое колесо 7, которые все контактируют друг с другом. Между дисками 6 и 7 закреплен барабан 8 (может и не быть), а вокруг него радиальные чашеобразные ветровые лопасти 9 (чаши, желоба, перегородки), образуя ветровое колесо. По сторонам ветровых лопастей 9 (ветроколес) в поперечных осях линии установки валов 1, на шарнирах 10 установлены направляющие щиты 11, ширина которых равна расстоянию между осями соседних вертикальных валов 1. Предусмотрена фиксация щитов 11 (на рис. 1 не показана). На одном из вертикальных валов 1 через зубчатую передачу 12 
подсоединен генератор 13 электрической энергии. Ветродвигатель монтируется вдоль северной стороны крыш или в наземных условиях фронтально розе ветров. Работа ветродвигателя поясняется с помощью рис. 2 и рис. 3.

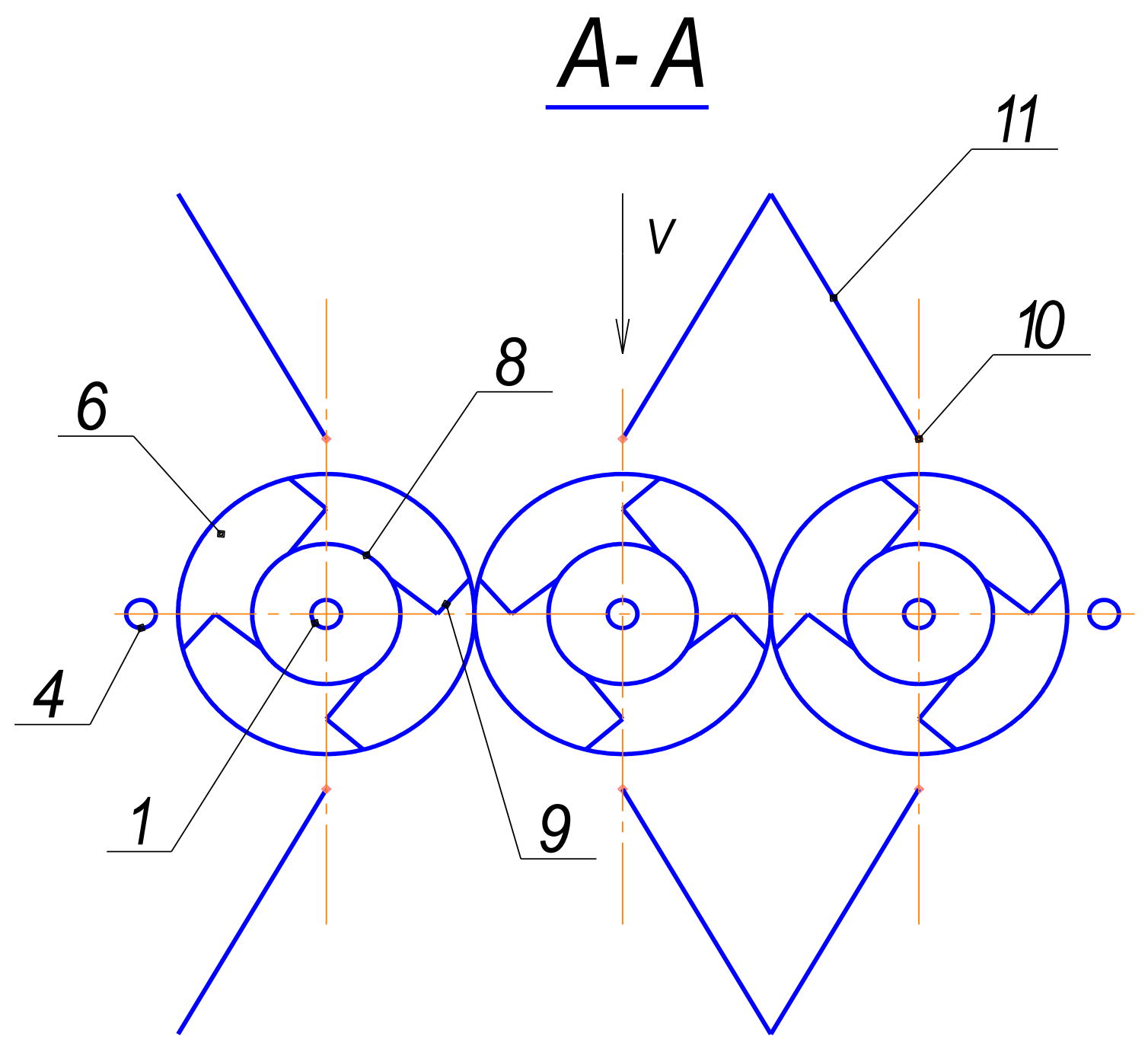

Рис. 2. Сечение ветродвигателя по А-А:

1- вертикальный вал; 4 - стойка; 6 - нижний диск; 8- барабан; 9 - радиальные чашеобразные ветровые лопасти; 10- шарниры; 11- направляющие щиты 


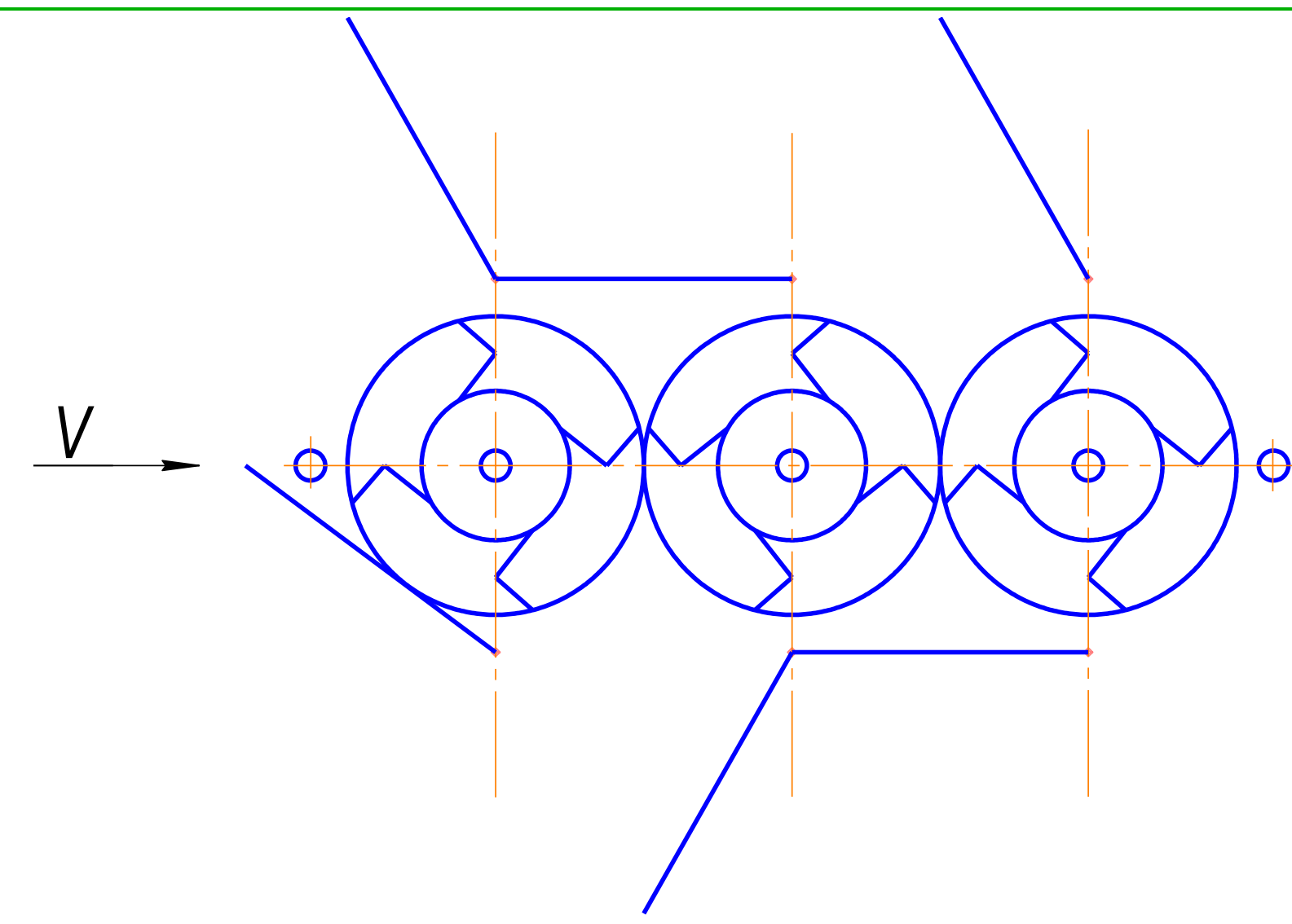

\section{Рис. 3. Сечение ветродвигателя по А-А} Варианты работы ветродвигателя

При фронтальном направлении ветра, или под каким-то углом, левые направляющие щиты 11 (рис. 2) отклоняют на ширину влево до перекрытия левой половины ветровых лопастей 9 первого ветроколеса вертикального вала 1, фиксируют. Правые направляющие щиты 11 отклоняют встречно друг другу до сближения их концов, фиксируют. Таким образом, два левых направляющих щита 11 образуют сопловое устройство и направляют ветер на чаши ветровых лопастей первого и второго ветроколеса слева. Такая картина наблюдается и в более правых колёсах при любом их количестве. В то же время направляющие щиты 11 закрывают от ветра вторые половины ветровых колес с обратным положением чаши ветровых лопастей 9, что устраняет их сопротивление встречному ветру. Ветровые лопасти 9 приводят во встречное вращение валы 1, мощность которых суммируется через зубчатые колеса.

При изменении направления ветра необходимо произвести перестановку направляющих щитов 11 согласно рис. 3, где ветровой поток направляется на пересечение продольного ряда валов 1 с полезным использованием ветровых 
лопастей 9 и устранение их вредного сопротивления. При ураганных ветровых явлениях ветровые лопатки 9 закрываются направляющими щитами 11 путём установки их вдоль валов 1, закрывая их между осями.

\section{Выводы.}

1. Оригинальность конструкции ветродвигателя заключается в выполнении его в виде ряда вертикальных валов, расположенных на одной геометрической продольной оси, снабженных зубчатыми колёсами, взаимодействующими между собой, в выполнении дисков и ветровых лопастей касательно между собой, по сторонам ветровых лопастей, в установке направляющих щитов, предусматривающих защиту ветровых лопастей от ураганных ветров.

2. Повышенная энергетическая эффективность автономной крышной ветроэлектростанции достигается путем выработки электрической энергии генератором при суммировании зубчатыми колесами мощностей всех вертикальных валов ветродвигателя.

3. За счет особенностей конструктивного исполнения ветродвигателя достигается также упрощение конструкции, монтажа, ремонта и обслуживания автономной крышной ветроэлектростанции.

\section{Список литературы}

1. Андрианова Л.П. Энергообеспечение децентрализованных потребителей на основе крышных ветродвигателей и солнечных электростанций / Л.П. Андрианова, В.Ю. Кабашов // Международный техникоэкономический журнал №1. Раздел Энергетика ; под ред. д-ра техн. наук, члена корреспондента РАН О.Н. Дидманидзе. - Москва : ООО «Спектр», 2019. - 92 с. C. $72-78$.

2. Андрианова Л.П. Перспективные технологии ветровых энергоустановок малой мощности для децентрализованных потребителей (Лучшая научная статья 2019) / Л.П. Андрианова, Р.Т. Хазиева // Сборник статей Международного научно-исследовательского конкурса (24 ноября 2019 г.). - Петрозаводск: МЦНП «Новая наука», 2019. - 291с., С.154-163.

3. Андрианова Л.П. Прогнозирование потребительского спроса сельских объектов при создании проектов децентрализованного энергоснабжения с возобновляемой энергетикой / Л.П. Андрианова, А.Т. Ахметшин, Д.Т. Атнагулов // Фундаментальная и прикладная наука: Новые вызовы и 
прорывы. Сборник статей Межд. научно-практ. конф. (26 января 2020 г.) - . Петрозаводск Российская Федерация МЦНП «Новая наука». В дух частях. Часть 2, 2020 - 368 с. - С. 10-19.

4. Андрианова Л.П. Социально-экономические аспекты гибридных микроэлектростанций с возобновляемой энергетикой для децентрализованного электроснабжения сельских объектов : (монография) / Л.П. Андрианова, А.Т. Ахметшин, А.Е. Усманова // Общество, экономика, право: Актуальные вопросы и векторы развития. Раздел II Актуальные вопросы современных социально-экономических процессов. - Петрозаводск: Российская Федерация МЦНП «Новая наука», 2020.- 244c. - С.112-141.

5. Андрианова Л.П. Крышная солнечная электростанция с автоматической системой слежения за солнцем / Л.П. Андрианова, В.Ю. Кабашов // Международный технико-экономический журнал. ТНЕ International Technical - Economic Journal; под ред. д-ра техн. наук, академика РАН О.Н. Дидманидзе. - №1, 2020. - Москва : ООО Мегаполис.- С.37-42.

(С Андрианова Л.П., Павлова 3.Х., Хакимьянов М.И., Хазиева Р.Т., 2020 